Fecha de recepción: abril 2020

Fecha de aceptación: mayo 2020

Versión final: junio 2020

\section{Construindo uma história arqueogenealógica do audiovisual educativo e científico na área das Ciências da Saúde no Brasil. Dimensões estética, política e pedagógica}

Marcia Bastos de Sá ${ }^{(1)}$ e Luiz Augusto

Coimbra de Rezende Filho ${ }^{(2)}$

Resumo: $\mathrm{O}$ artigo apresenta um panorama da elaboração de abordagem teórica e analítica para pesquisas sobre a produção do audiovisual educativo destinado à área das Ciências da Saúde, a partir de noções do referencial foucaultiano. Tomando-se como pressupostos fundamentais que (1) toda fabricação humana é histórica e política, sendo produzida e produzindo saberes segundo configurações e contingências do seu tempo, e que (2) os audiovisuais guardam histórias de saberes e poderes, realizou-se pesquisa sobre materiais e acervos audiovisuais em busca da descontinuidade histórica presente no domínio do arquivo no âmbito dos saberes e das práticas. Apresentam-se as operações teóricas relevantes, os dados empíricos produzidos pelas investigações e os resultados obtidos nos últimos 5 anos da pesquisa. Generalizando os resultados pode-se afirmar (1) que os audiovisuais não são testemunhos diretos do que dizem ou mostram, mas evidenciam a natureza dos gestos políticos e estéticos que os constroem, (2) que uma dupla abordagem histórica - epistemológica e arqueológica - reforça a possibilidade da construção de uma leitura historiográfica do audiovisual, e (3) que filmes expressam dimensões sociais da produção científica, elementos importantes para compreender como a ciência se relaciona com a política, a sociedade, a cultura e o poder na sua própria contemporaneidade.

Palavras chave: Produção audiovisual - Educação em ciências da saúde - História epistemológica - História arqueogenealógica - Michel Foucault.

[Resumos em espanhol e inglês na página 55]

${ }^{(1)}$ Marcia Bastos de Sá. Graduada em Psicologia (UFRJ) e Fisioterapia (SUAM); Especialista em Tecnologia Educacional nas Ciências da Saúde, Mestrado e Doutorado em Educação em Ciências e Saúde, pelo Instituto NUTES de Educação em Ciências e Saúde (UFRJ). Pós-doutorado no Laboratório de Vídeo Educativo do NUTES-UFRJ. Colaboradora Voluntária no NUTES-UFRJ.

(2) Luiz Augusto Coimbra de Rezende Filho. Professor Associado do Instituto NUTES de Educação em Ciências e Saúde (UFRJ). Graduado em Comunicação Social-Cinema 
(UFF), com Mestrado e Doutorado em Comunicação e Cultura (UFRJ). Pós-doutorado na Pontifícia Universidad Católica de Chile. Bolsista em Produtividade de Pesquisa pelo CNPq.

\section{Antecedentes}

Entre 2008 e 2011 foi realizada pesquisa que tomou vídeos do acervo do Laboratório do Vídeo Educativo do Núcleo de Tecnologia Educacional para a Saúde (LVE-NUTES) da Universidade Federal do Rio de Janeiro como fontes primárias para uma reconstrução da história do NUTES, privilegiando-se uma análise das relações micro e macropolíticas contemporâneas aos títulos apreciados. Para tanto, conjugou-se à análise fílmica dos vídeos, pesquisa documental, assumindo-se noções do referencial foucaultiano, como biopolítica, governo e governamentalidade (Sá, 2011).

Rezende et al. (2012) analisaram o filme Combate à Lepra no Brasil (1945) visando uma reflexão a respeito do uso de audiovisuais de arquivo como fonte para o ensino da história da ciência, pela "retomada das principais características das abordagens historiográficas epistemológica e arqueológica", e de pesquisa documental preliminar sobre o conhecimento científico contemporâneo ao filme.

A partir desses trabalhos percebeu-se que a produção do audiovisual educativo e científico para as Ciências da Saúde no Brasil constitui uma história que se espraia desde o início do século XX até os dias atuais e que essa história guarda, devido à complexidade característica do suporte audiovisual, elementos e/ou camadas de saberes e poderes de vários níveis e esferas, que uma vez acessados, poderiam enriquecer a análise, a compreensão e o próprio uso do audiovisual educativo. Mas, para isso, seria preciso elaborar uma abordagem teórico-metodológica para acesso, análise e comparação de dados condensados em produções audiovisuais.

Tendo por finalidade aprofundar as investigações sobre o audiovisual educativo e científico na área das Ciências da Saúde e, concomitantemente, desenvolver a abordagem teórico-metodológica necessária para isso, no final de 2013 elaborou-se um projeto de pesquisa que tinha como recorte inicial a análise de um conjunto de vídeos do LVE produzidos para os Projetos Ensino-Serviço sobre as patologias Hanseníase, Tuberculose e AIDS. Observou-se, contudo, que esse recorte não era o mais profícuo para o avanço do desenvolvimento de uma metodologia de base foucaultiana para análise de audiovisuais. Simultaneamente constatou-se que a análise de um filme isolado não era capaz de responder a algumas perguntas, o que apontou para a importância de ampliação de uma proposta metodológica em direção a um tipo de pesquisa que procedesse por meio da análise de séries de filmes, encontrando-se sustentação em Pierre Sorlin (2005). Por considerar que existem questões que podem ser mais bem investigadas por meio de séries de filmes, o autor propõe um método composto por três etapas: a eleição de uma amostra de filmes; a verificação comparativa de aspectos dos filmes; e a testagem da análise em apenas um filme, antes de realizar a análise da série construída. 
Apesar do método de Sorlin ser proposto para o cinema comercial de ficção, foi possível adaptar seus princípios gerais para a análise de documentários. No caso da presente pesquisa, os critérios para a seleção dos filmes e para a consequente formação de séries, se referem a aspectos que correspondem analogamente aos estabelecidos pelo autor. Definiu-se também que o caráter discursivo e institucional dos acervos seria considerado pela relevância que alguns assuntos, áreas de conhecimento, produtores e/ou diretores podem adquirir dado o número de ocorrências que contam dentro de um acervo.

Para estender considerações referidas inicialmente a materiais únicos para uma análise de acervos audiovisuais como conjuntos e séries de obras, realizou-se, entre abril e julho de 2014, levantamento em três acervos avaliados como importantes para uma investigação da história do audiovisual brasileiro para o ensino de Ciências da Saúde, a saber: o da Cinemateca Brasileira (CB); o do LVE/NUTES; e o do Banco de Recursos Audiovisuais para a Saúde do Instituto de Comunicação e Informação Científica e Tecnológica em Saúde (BRAVS/ICICT). Com o levantamento de informações sobre esses acervos em seu conjunto, buscaram-se formas de identificar séries de obras para análise, entendendo-se como série o conjunto formado por filmes que compartilham um número determinado de características.

O acervo da CB é formado por cerca de 30 mil títulos; sua página na WEB dá acesso à base de dados Filmografia Brasileira, que disponibiliza informações sobre a produção audiovisual nacional desde 1897 até dias atuais. O acervo do LVE/NUTES é composto por 219 títulos produzidos pela própria instituição entre 1975 e 2000, e o acesso aos seus dados é feito por meio de catálogo disponível eletronicamente. O acervo on-line do BRAVS/ ICICT, sistema de busca da VídeoSaúde Distribuidora, foi criado em 1996, e disponibiliza dados de 4000 títulos audiovisuais. Embora tenha sido realizado o levantamento nos três acervos, até o momento só foram apreciados detalhadamente os resultados obtidos nos acervos da CB e do LVE. A amostra geral foi constituída por 1109 títulos com a seguinte contribuição: CB - 468 títulos; LVE - 219 títulos; BRAVS - 422 títulos.

Pelo cotejamento dos dados dos três acervos, observou-se que algumas doenças se destacam e podem formar séries de filmes e, dentre estas, optou-se por estabelecer para a presente pesquisa uma série de sete filmes sobre Hanseníase, composta pelos títulos "Combate à lepra no Brasil", do acervo da CB e os seis vídeos do LVE referidos ao tema, considerando que essa patologia: (a) é a segunda mais tratada nos três acervos audiovisuais investigados (CB, LVE e BRAVS); (b) ainda hoje permanece na pauta de pesquisadores, movimentos sociais e organizações de saúde, pois continua afetando a população; (c) possui uma história social que marcou períodos, produziu discursos, práticas, preconceitos, silêncios, etc.; (d) continua demandando atenção da sociedade, o que leva à produção pulverizada de novos materiais destinados à informação e orientação da população sobre cuidados necessários à manutenção ou recuperação da saúde. Além disso, considerou-se que a ampliação do recorte temporal possibilitaria uma melhor apreciação de mudanças científicas e sociopolíticas, favorecendo o desenvolvimento das análises. 


\section{Suporte teórico-metodológico}

A pesquisa também assume contribuições de Jacques Le Goff, Marc Ferro, Georges Didi-Huberman, Jean-Louis Comolli a respeito dos tópicos: documento e documento audiovisual; cinema e história; imagem de arquivo e história; documentários científicos de arquivo. Também foram operacionalizadas noções da arqueologia foucaultiana para abordagem do audiovisual: discurso e enunciado; a priori histórico e arquivo; campos correlacionais.

Em relação à noção de documento, assume-se a ampliação que passa a considerar além dos textos escritos, ilustrações, imagens, transmissões sonoras e qualquer outro tipo de registro. Esse alargamento culminou com uma revolução documental que associada à revolução tecnológica introduzida pela informática, possibilitou o surgimento de uma história que pôs em causa a noção de documento e do seu tratamento, em favor da valorização da relação de documentos com séries de outros que os precedem e o seguem (Le Goff, 1990, pp. 541-542).

Sob esse enfoque, documentos são considerados como monumentos, entendendo-se que "o que transforma o documento em monumento" é "a sua utilização pelo poder" e que, exatamente por isso, documentos devem ser apreciados como produtos da sociedade que os fabricou "segundo as relações de forças que aí detinham o poder" (Id. Ibid. p. 545). Para chegar à análise das condições de produção dos documentos-monumentos, deve-se proceder à crítica do documento, ou seja, deve-se elaborá-lo, organizando-o, recortandoo, distribuindo-o, ordenando-o e repartindo-o em níveis, em séries, definindo unidades e descrevendo relações que ele estabelece (Foucault, 2005).

Ao estudar a relação cinema-história, Ferro (1992) destaca que o trabalho sobre essa relação deve partir das imagens, ultrapassando o entendimento de que elas servem para ilustrar, confirmar ou desmentir saberes da tradição escrita; as imagens precisam ser consideradas exatamente como são, mesmo que seja necessário lançar mão de outros saberes para melhor compreendê-las. Seguindo essa lógica, os filmes devem ser estudados em associação com o mundo que os produz, sob a hipótese de que "o filme, imagem ou não da realidade, documento ou ficção, intriga autêntica ou pura invenção, é História”, assumindo-se o postulado "de que aquilo que não aconteceu [...], as crenças, as intenções, o imaginário do homem, são tão História quanto a História” (Id. Ibid. p. 80).

Assim, um filme tem valor tanto "por aquilo que testemunha", como "também pela abordagem sócio-histórica que autoriza", e a análise de filmes não precisa incidir "sobre a obra em sua totalidade", podendo se apoiar sobre "extratos, pesquisar 'séries', compor conjuntos", tomando-se como objeto de análise "tanto a narrativa quanto o cenário, a escritura, as relações do filme com aquilo que não é filme: o autor, a produção, o público, a crítica, o regime de governo", pois, sem isso, não se pode chegar à compreensão da obra e da realidade que ela representa (Id. Ibid.)

Por considerar que a imagem não é tudo e não diz tudo, Didi-Huberman (2003, p. 85) defende que é legítimo observá-las e questioná-las "como fatos característicos e como depoimentos cheios" de história, assumindo-se como princípio que "todo ato de imagem é arrancado da descrição impossível de um real” (Id. Ibid. p. 156). Para o historiador, a imagem deve ser olhada por aquilo que é: um arquivo que mostra uma parcela da realidade, 
pois sempre que mostra algo, vela também outra coisa, não podendo, portanto, mostrar tudo ou velar tudo. Ademais, para falar, a imagem tanto precisa ser posta em relação "com outros elementos, outras imagens e temporalidades, outros textos e depoimentos" (Lins et al., 2011, p. 57) como precisa ser desmontada, pois o exercício da desmontagem pressupõe que "se precisamos montar imagens é porque as imagens desmontam" (Campos, 2017, p. 271).

Partindo das premissas de que "não há documento sem olhar" e "não há cinema sem espectador", Comolli (2008) entende que "desenvolver um olhar crítico sobre o documento cinematográfico é analisar nas condições de sua produção o momento único do próprio registro", e também "as condições da tomada, duração, gestos, movimentos, luzes, bordas dos enquadramentos, auto-mise en scène dos corpos, extracampo", pois a atitude necessária em relação à imagem, não deve ser nem a da aceitação ingênua, nem a da recusa obstinada, posto que "o que está em jogo é o trabalho com a dimensão concreta das singularidades que compõem o documento audiovisual", envolvendo "a história complexa dos olhares que se colocaram sobre o documento".

Tomando por base as contribuições destacadas, a presente pesquisa entende que: (1) "filmes e vídeos produzidos no passado podem ser tratados como documentos históricos, e não apenas como instrumentos para a transmissão de conhecimento", admitindo-se, contudo, que isso não significa entendê-los como representações dos fatos ou da ciência, posto que filmes "não são testemunhos diretos e neutros da história ou de 'como as coisas ocorreram"'; (2) filmes são reconstruções e, além disso, possuem uma dimensão comunicativa e intencional que explica pelo menos em parte por que eles são como são, sendo esta uma das dimensões que precisa ser levada em conta quando se considerar tanto o uso educativo dos audiovisuais, quanto seu papel na divulgação científica e na constituição de fontes históricas (Rezende et. al. 2012, passim).

Ainda que não possam ser entendidos como testemunhos diretos da História, (3) filmes podem ser entendidos como testemunhos "de uma maneira de vê-la ou escrevê-la, em um determinado momento", se e quando entendidos como discursos em que aspectos referidos a elementos científicos, políticos e econômicos de uma época podem ser identificados. Tal entendimento envolve "um trabalho analítico sobre as 'versões' da história presentes nos filmes" e uma "definição clara do contexto, das perspectivas e dos pressupostos que se articulam para a construção do filme e do que nele é visível ou não", o que possibilita a "evidenciação de que nunca se trabalha com a História como um todo, mas com recortes e análises que dependem dos objetivos e das ferramentas do analista" (Rezende et. al. 2012, passim).

Em suma, entende-se que (4) "métodos análogos aos desenvolvidos por historiadores, como a análise, montagem e desmontagem dos documentos fontes da história, podem ser aplicados ao campo do audiovisual", pois (5) audiovisuais podem ser considerados "fontes documentais vivas" quando trabalhados por meio de uma análise historiográfica que proceda por sua desmontagem e remontagem, e "pela pesquisa de fontes exteriores ao filme que iluminem seus próprios pressupostos" (Rezende et al. 2012, passim).

Além disso, ressalta-se que "documentários científicos parecem estar marcados por uma tensão entre representação e comunicação, entre endereçamento e espectador", o que os faz possuir tanto uma "dimensão representativa com seus referentes e objetos", como uma 
dimensão comunicativa, ou seja, "um interesse ou ideal de comunicação com o espectador", sendo a relação entre estes dois polos mantida por "uma forma particular de tensão ou indeterminação." Assim, (6) propõe-se "representação como conformação, organização, encenação de ideias de acordo com um plano/projeto pré-concebido" e "endereçamento como uma intenção deliberada de comunicar a um grupo específico usando recursos que se julgam apropriados para a recepção de forma determinada por esse grupo", advertindo-se que (7) "a compreensão do cinema científico como fonte histórica passa por uma análise da tensão entre estes dois polos de expressão: o representacional e o endereçamento" (Rezende, 2014, pp. 452-453, passim).

\section{Noções foucaultianas operacionalizadas}

Após usar o termo discurso de diferentes modos em diferentes situações, Foucault acaba por defini-lo como um "conjunto de enunciados que se apoiam em um mesmo sistema de formação" que é histórico, a um só tempo "fragmento, unidade e descontinuidade na própria história", tornando-se prioritário "o problema de estabelecer seus limites, seus cortes, suas transformações, e os modos específicos de sua temporalidade" (Foucault, 2005, p. 133).

Em relação ao enunciado, o autor adverte que ele "está sempre dentro de unidades descritas pela gramática ou pela lógica" - como uma frase, uma proposição ou um ato de formulação, "ou mesmo em sequências de signos que não obedecem a suas leis", caracterizando "não o que nelas se apresenta ou a maneira pela qual são delimitadas, mas o próprio fato de serem apresentadas, e a maneira pela qual são." Considerar os enunciados em si mesmos significa buscá-los na periferia e na superfície do limite da linguagem e não em sua organização interna e conteúdo, porque o nível enunciativo tem a linguagem como instância de aparecimento e seu modo de ser (Id. Ibid. pp.123-126, passim).

Descrever um enunciado significa "definir as condições nas quais se realizou a função que deu a uma série de signos [...] uma existência específica”, entendendo-se que se por um lado o enunciado não se oculta por trás ou por baixo das performances verbais, por outro, ele também "não é imediatamente visível" porque "não se apresenta de forma tão manifesta quanto uma estrutura gramatical ou lógica", o que o torna, ao mesmo tempo "não visível e não oculto". Como o enunciado "não se oferece à percepção como portador manifesto de seus limites e caracteres", é necessária uma "certa conversão do olhar e da atitude para poder reconhecê-lo e considerá-lo em si mesmo" (Id. Ibid. pp. 123-126, passim). A análise de enunciados não pretende uma descrição total e exaustiva do que foi dito, mas sim uma abordagem das performances verbais num nível específico de descrição, que dissocie sua complexidade, isole os termos que aí se entrecruzem e demarquem as várias regularidades a que obedecem. Essa análise se refere "a coisas ditas, a frases que foram realmente pronunciadas ou escritas, a elementos significantes que foram traçados ou articulados", na singularidade que os faz existirem, serem observados, lidos e eventualmente reativados para usos ou transformações possíveis (Id. Ibid. pp. 123-124).

A positividade de um discurso é caracterizada por sua unidade através do tempo e por sua expansão para além das obras individuais, dos livros e dos textos. Toda a massa de textos 
de um mesmo domínio discursivo se comunica por uma forma de positividade que define um campo em que podem ser desenvolvidas identidades formais, continuidades temáticas, translações de conceitos, jogos polêmicos; essa positividade desempenha o papel do que se poderia chamar um a priori histórico (Id. Ibid. p. 143).

A noção de a priori histórico designa a condição de realidade para enunciados de uma história determinada referindo-se às coisas efetivamente ditas; ela deve "dar conta dos enunciados em sua dispersão, em sua superposição e substituição recíproca, em sua simultaneidade e sucessão que não é dedutível", pois o discurso não possui apenas um sentido ou uma verdade, mas uma história específica. Sob essa perspectiva, o a priori foucaultiano se constitui, como o conjunto transformável "das regras que caracterizam uma prática discursiva, entendendo-se que essas regras não se impõem do exterior aos elementos que elas correlacionam, pois já estão inseridas no que ligam, modificando-os e com eles se transformando em certos limiares decisivos" (Id. Ibid. pp. 143-145, passim).

Denomina-se arquivo o conjunto de todos os sistemas de enunciados; é ele que faz com que as coisas ditas apareçam segundo regularidades específicas do nível discursivo definindo as possibilidades e impossibilidades enunciativas que ele conduz. Entendido como "a lei do que pode ser dito, o sistema que rege o aparecimento dos enunciados como acontecimentos singulares", o arquivo é o que "faz com que todas as coisas ditas não se acumulem indefinidamente em uma massa amorfa, não se inscrevam em uma linearidade sem ruptura e nem desapareçam ao simples acaso de acidentes externos"; é ele "que faz com que figuras distintas se agrupem, se componham umas com as outras segundo relações múltiplas, se mantenham ou se esfumem segundo regularidades específicas" (Id. Ibid. p. 146).

O arquivo se dá por fragmentos, regiões e níveis, e com mais clareza na medida em que o tempo dele nos separa; sua descrição e análise comportam essa região privilegiada, ao mesmo tempo próxima de nós e diferente de nossa atualidade, pois é aquilo que, fora de nós, nos delimita. Assim, o limiar de existência do arquivo é instaurado pelo corte que nos separa do que não podemos mais dizer e do que fica fora de nossa prática discursiva; começa com o exterior da nossa própria linguagem e seu lugar é o do afastamento de nossas próprias práticas discursivas (Id. Ibid. pp. 146-149, passim).

Tendo o arquivo como "a lei do que pode ser dito", situa-se o princípio de raridade que supõe que "nem tudo é sempre dito", pois por mais numerosos que sejam os enunciados, eles sempre estão em "déficit", ou seja, em menor quantidade, em relação a tudo o que é ou foi possível dizer. Disso decorre que é preciso analisar a disponibilidade dos arquivos, dos documentos e das imagens como o produto das condições que possibilitaram/ conformaram justamente a existência e a conservação dos documentos/ filmes exatamente da maneira como são. Analisar as condições de raridade ou de rarefação dos documentos ou dos arquivos é distinguir entre tudo o que se podia "dizer", o que foi dito, porque foi dito exatamente da maneira como foi e não de outra (Id. Ibid. p. 135)

O correlato do enunciado - aquilo a que se refere, o que é posto em jogo por ele, não apenas o que é dito, mas aquilo de que fala, seu tema - é o que permite dizer se uma proposição tem um referente ou não. É preciso então saber a que se refere um enunciado, qual é seu espaço de correlações, para poder dizer se uma proposição tem ou não um referente. Contudo, a relação da proposição com o referente não pode servir de modelo e de lei à re- 
lação do enunciado com o que enuncia, pois essa última não só é de nível diferente, como também a precede. Correlatos dos enunciados abrem campos correlacionais que formam o conjunto de domínios em que objetos e referentes podem aparecer e em que as relações podem ser assinaladas (Id. Ibid. pp. 101-105). Um enunciado está originalmente vinculado a um referencial que não é constituído de coisas, fatos, realidades ou seres, mas sim "de leis de possibilidade, de regras de existência para os objetos que aí se encontram nomeados, designados ou descritos, para as relações que aí se encontram afirmadas ou negadas"; o referencial do enunciado forma, portanto, "o lugar, a condição, o campo de emergência, a instância de diferenciação dos indivíduos ou dos objetos, dos estados de coisas e das relações que são postas em jogo pelo próprio enunciado, definindo as possibilidades de aparecimento e de delimitação" do que dá sentido e valor de verdade à proposição. Esse é o "conjunto que caracteriza o nível enunciativo da formulação: através da relação com esses diversos domínios de possibilidade, é o enunciado que define o que pode, ou não, ter sentido e receber ou não um valor de verdade" (Id. Ibid. p. 103).

Propõe-se que se considere que os gestos de apropriação dos documentos e dos arquivos, e não só o momento de sua produção, produzem campos correlacionais, estendendo a premissa foucaultiana de que os enunciados não teriam objetos ou referentes, mas correlatos ou campos de correlações, para os documentos audiovisuais. Assim, pode-se entender que uma imagem, um documento, um arquivo, estabelecem campos de correlações a priori e que um campo tem a ver com as características formais, temáticas, históricas, estéticas do documento. Contudo, este campo não se reduz ao referente, ao seu tema, objeto ou conteúdo do documento, pois embora estes elementos se relacionem de alguma forma dentro do campo, o valor e o sentido do documento residem nas relações em potência presentes no campo e em outros elementos não imediatamente visíveis na imagem, mas que a ela se associam por meio do campo de correlações. Desta forma, por exemplo, os documentos guardam filiações estéticas específicas com outros documentos, reafirmam práticas sociais compartilhadas e podem pertencer a conjuntos mais amplos de documentos que se complementam (Rezende, 2013).

Sob essa perspectiva, um dos sentidos para a operacionalização da análise de materiais audiovisuais pode se concentrar sobre as diferenças entre o campo inicialmente dado (se ele puder ser pelo menos parcialmente identificado) e o novo campo de correlações que é criado ou recriado pelo gesto apropriativo. Ao enfatizar não a sua autenticidade ou identidade, mas as leituras a que documentos são expostos e submetidos, a análise dos campos de correlações pode ser entendida como uma forma de realizar a crítica dos documentos no campo do documentário científico (Foucault, 2005; Le Goff, 1990).

Um campo de correlações pode ser entendido, portanto, como o conjunto de relações exteriores estabelecido por uma imagem, um documento ou um arquivo no momento de sua produção ou no momento em que são reapropriados. Por este motivo, campos correlacionais existem apenas em potência, virtualmente, diferentemente dos referentes, e surgem apenas quando os documentos são submetidos a uma determinada questão/ problema. Em suma, um campo correlacional tem a ver com as características formais, temáticas, históricas, estéticas do documento, com o gesto que o criou, mas também com o gesto estético-político que o "recriou" por meio de uma reapropriação. 


\section{Princípios de análise e procedimentos metodológicos}

Partindo dos pressupostos de que materiais audiovisuais são documentos e de que toda fabricação humana é histórica, sendo produzida e produzindo saberes segundo configurações e contingências do seu tempo, propôs-se a análise de uma série de filmes com finalidades pedagógicas sobre hanseníase. Essa análise visou tanto uma investigação das condições de possibilidade do surgimento e da transformação dos saberes veiculados nos materiais, como uma análise histórica das condições políticas de possibilidade dos mesmos. Para isso, buscou-se identificar o que os filmes documentam (do que se pode dizer que eles são documentos) e analisar como os enunciados extraídos dos filmes definem campos de correlações. Para realizar essa pesquisa, fez-se um levantamento de informações sobre a contemporaneidade dos filmes, suas condições de possibilidade, para notar como cada filme se opõe ou se filia a outros discursos, saberes, práticas e situações/condições históricas que lhe foram contemporâneos. A partir deste procedimento, buscou-se extrair alguns enunciados por meio da análise das relações entre texto e imagem existentes nos filmes e os campos de correlações encontrados.

Os princípios de análise se concentraram nas seguintes premissas: (1) filmes funcionam como filtro: foram buscadas informações sobre os temas, imagens e questões que cada filme efetivamente tem e evidencia; (2) existe uma tensão entre o que é mostrado e o que não é mostrado nos filmes: por meio do contraste entre as informações presentes em cada filme e as que chegam por meio do levantamento de outros documentos podem-se perceber deslocamentos, invisibilidades, silenciamentos; (3) dos erros conceituais eventualmente encontrados nos filmes, não importa saber como ou se eles distorcem a realidade, mas, num esforço de saber o que eles documentam, identificar campos correlacionais, endereçamentos, projetos políticos, ou seja, tomá-los também como enunciados. Em resumo, considerou-se que filmes testemunham sobre um determinado estado do conhecimento e/ou sobre as relações deste com a sociedade e as políticas públicas de sua época.

\section{Os filmes analisados}

\section{Combate à lepra no Brasil (1945)}

Filme dirigido pelo cineasta Humberto Mauro e produzido pelo Instituto Nacional de Cinema Educativo (INCE) e pelo Serviço Nacional de Lepra (SNL), órgãos ligados ao então Ministério da Educação e Saúde (MES). O objetivo principal do filme era divulgar a rede de leprosários que estava se constituindo no Brasil como medida fundamental para o combate à hanseníase no Brasil. O filme, como uma produção histórica e socialmente datada, reflete o contexto de uma época marcada por uma grande preocupação com as doenças tropicais e em que ainda era forte a influência da política higienista, nascida nos anos 1920 (Moraes, 2007). 
Enunciados extraídos: $\mathrm{O}$ aparelhamento das práticas do isolamento compulsório de Hansenianos - uma prestação de contas; Doentes bem tratados; O racismo científico; O caminho certo para a erradicação da Lepra.

A análise dos enunciados foi desenvolvida a partir de referências que possibilitassem uma compreensão de como a lepra era entendida e tratada, e como eram as práticas estatais e sociais em relação à doença, em nível nacional e internacional à época do filme.

\section{Os vídeos do LVE-NUTES}

Em linhas gerais, os vídeos do LVE/NUTES sobre a hanseníase visam três objetivos principais: (1) capacitação técnica dos profissionais de saúde pela divulgação de conhecimentos, estratégias e práticas destinadas ao tratamento e controle da enfermidade; (2) sensibilização do mesmo público-alvo para aspectos emocionais, culturais, sociais e econômicos envolvidos ou ocasionados pela patologia; e (3) sensibilização dirigida à reflexão e à crítica da própria prática médica.

Os títulos Prevenção de incapacidades físicas em hanseníase (1988a), Aspectos clínicos e semióticos do diagnóstico da hanseníase (2001a) e Simplificando o diagnóstico da hanseníase (2001b) foram apreciados, mas não analisados segundo seus enunciados, por que: o primeiro é entendido como material estritamente instrucional em que são apresentados os procedimentos de exame e de investigação para diagnóstico precoce e prevenção de deformidades decorrentes da hanseníase; os dois seguintes, porque abordam práticas e aspectos diagnósticos e terapêuticos já trabalhados em vídeos anteriores (1988b e 1995), desenvolvendo abordagens distintas: o primeiro é elaborado a partir da consecução de planos de entrevistas e/ou depoimentos, que contrastam entre si, concedidos por alunos e profissionais; o outro, elaborado para servir como material de apoio em cursos de capacitação em hanseníase para profissionais de saúde, assumindo um formato inédito no acervo - a utilização da imagem em movimento sem acréscimo de som e a ausência de textos explicativos a respeito do conteúdo (Sá, 2018).

\section{Pra onde é que eu vou? (1988)}

Vídeo produzido em parceria entre a Divisão Nacional de Dermatologia Sanitária do Ministério da Saúde (DNDS-MS) e o NUTES-UFRJ, constituindo junto com o vídeo Prevenção de incapacidades físicas em hanseníase e o livro Controle da hanseníase, o conjunto de recursos educativos produzidos para o Projeto de Integração Ensino-Serviço (IES) sobre hanseníase. O título analisado foi denominado como um "vídeo de sensibilização", tendo por objetivo favorecer debates e reflexões acerca da problemática vivida por portadores e ex-portadores da doença e, especialmente, sobre a complexidade dos determinantes envolvidos no processo de adoecimento, tendo em vista as ações necessárias para seu tratamento e controle.

Destinado especialmente a profissionais e estudantes da área da saúde, o vídeo aborda o tema do preconceito e do desconhecimento em relação à doença e ao seu portador. É es- 
truturado em três sequências: na de abertura, apresenta-se depoimento de ex-hanseniano que expõe o drama pessoal e social vivido pelos que foram submetidos ao isolamento compulsório; na segunda, apresentam-se respostas de transeuntes a respeito da doença; ao final, por meio da encenação de um caso clínico, a hanseníase é abordada como uma doença curável, além de serem fornecidas informações sobre o seu diagnóstico e tratamento, e retomado do problema do preconceito.

Enunciados extraídos: Consequências do isolamento compulsório de hansenianos: o sofrimento dos doentes; A mudança terminológica não acaba com a desinformação, preconceito e medo da população; A erradicação da doença no Brasil depende do esclarecimento da população e, em especial, da reorientação científica e tecnológica dos serviços e profissionais de saúde.

\section{Os desafios da cura (1995)}

Este vídeo propõe uma apreciação do conceito de cura da hanseníase, priorizando uma perspectiva centrada no diagnóstico precoce e, consequentemente, na cura total do paciente, evitando o desenvolvimento de sequelas. São retomados do vídeo anterior aspectos referidos ao desconhecimento da doença e à vinculação dos termos "lepra" e hanseníase. A estratégia de desenvolvimento do vídeo apresenta: imagens de dinâmica de grupo com pacientes hansenianos em tratamento, conduzida por médicos e assistentes sociais; depoimentos de pacientes em tratamento ou já curados entremeados por reflexões sobre dificuldades sociais, especialmente trabalhistas, vivenciadas por hansenianos ou exhansenianos; depoimentos de especialistas em direito trabalhista. Observa-se aumento do número de pacientes que depõem no vídeo e aumento do número de cenas filmadas em comunidade, mostrando especialmente, crianças brincando na rua e mães com filhos em unidade de saúde. Esses elementos podem ser entendidos como um investimento na inclusão da "realidade" vivida pelos pacientes em substituição ao recurso da encenação utilizado no título de 1988. Destaca-se também o uso de música para anunciar ou marcar passagens de assuntos e uso de locução para introduzir ou dar fechamento às sequências com comentários afirmativos que destacam elementos fundamentais para o atendimento adequado ao portador de hanseníase.

Enunciados extraídos: A cura da hanseníase depende do compromisso dos profissionais de saúde, dos portadores da doença e suas famílias e de toda a sociedade; O controle da hanseníase no Brasil depende da reorientação social, científica e tecnológica dos profissionais de saúde; Os portadores da doença devem lançar mão de mecanismos jurídicos para cobrar e garantir seus direitos sociais.

\section{(des)Mancha Brasil (1999)}

Este vídeo documenta atividades de Projeto de Extensão da Universidade Federal do Rio de Janeiro, em Queimados, município da Baixada Fluminense do Rio de Janeiro. O título faz referência e dá visibilidade ao Projeto (des)Mancha Brasil, criado em 1996, uma par- 
ceria interinstitucional e interdisciplinar que visa à eliminação da hanseníase em Queimados e Belford Roxo. O material foi financiado pelo Ministério da Saúde, em 1999, e produzido pelo NUTES em parceria com outras instituições.

A abordagem elaborada no material dá acesso a discursos e práticas dos participantes do Projeto, professora, estudantes de Medicina e profissionais de saúde, durante o desenvolvimento de diferentes ações em diversas localidades. Com isso, práticas encenadas ou apenas referidas verbalmente em vídeos anteriores são substituídas por ações de fato realizadas, visando um favorecimento para modificação de atitudes e práticas desfavoráveis em relação à doença.

Em linhas gerais, o vídeo dá visibilidade a duas atividades principais: ações educativas e exame clínico de pessoas com manchas na pele. As ações educativas visam à divulgação e ao esclarecimento sobre sinais, sintomas e forma de contágio da doença, tanto para a população em geral - em escola, posto e feira de saúde, e programa em rádio comunitária como para graduandos de Medicina - durante consultas supervisionadas - e profissionais de saúde - em curso de capacitação. O exame clínico para avaliação de manchas na pele também ocorre em vários espaços e situações: no posto de saúde, na feira de saúde, e em visitas domiciliares.

São inúmeras as cenas que mostram profissionais de saúde examinando manchas de pele sem o uso de luvas, posto que o exame não se sustente apenas no olhar: as manchas de pele precisam ser tocadas superficialmente, alisadas, esticadas, esfregadas, raspadas com as unhas. Em alguns momentos, após terem feito contato com as manchas de pele, os graduandos e profissionais tocam em si mesmos. Essas cenas e a proximidade física entre os representantes do saber médico e os pacientes mostram aquilo que resumidamente se informa sobre o contágio: essas cenas foram elaboradas para ativar, pela via imagética, o enunciado "não se pega hanseníase pelo contato físico", visando efeito que pela via verbal não logrou êxito pleno até então.

Enunciados extraídos: A erradicação da doença no Brasil depende de esclarecimento da população; A erradicação da doença no Brasil depende da reorientação social, científica e tecnológica dos profissionais de saúde; Não se pega hanseníase por contato físico; A erradicação da doença no Brasil depende de decisão política e econômica dos governos e da reorganização dos serviços de saúde.

\section{Cotejamento dos enunciados dos vídeos}

Em relação aos enunciados dos vídeos do acervo LVE/NUTES pode-se afirmar que não existe uma ruptura, uma descontinuidade, em relação à abordagem da hanseníase no acervo. A continuidade observada, contudo, segue no sentido de retomada, espraiamento e aprofundamento de tópicos e aspectos referidos à doença. Observa-se que por um lado cada vídeo discrimina melhor aspectos que foram apresentados nos anteriores, como a questão de que a erradicação da doença depende do esclarecimento da população e, em especial, da reorientação científica e tecnológica dos serviços e profissionais de saúde - fio mestre de todos os vídeos. Em relação às retomadas merece destaque a apresentação da 
máxima "Não se pega hanseníase por contato físico" como um enunciado visual no vídeo de 1999, estratégia não tentada em vídeos anteriores, podendo ser entendida como um acontecimento de ruptura no sentido proposto por Foucault (Castro, 2009, p. 24), Por outro lado, alguns tópicos comparecem apenas em um dos vídeos, como por exemplo: as consequências do isolamento compulsório, no de 1988; a orientação para a busca por mecanismos jurídicos para cobrar e garantir direitos sociais, no de 1995; e a indicação de que a erradicação da doença depende de decisão política e econômica dos governos e da reorganização dos serviços de saúde, no de 1999.

A análise e o cotejamento dos enunciados destacados dos filmes permitiram o delineamento do deslocamento de saberes e poderes referidos à hanseníase no Brasil, dos quais destacam-se:

(i) a adoção da poliquimioterapia (PQT) pela Organização Mundial de Saúde em 1981, diminuiu drasticamente o tempo de tratamento da doença e permitiu uma reorganização dos serviços local e regional para tratamento de pacientes (Maciel et al., 2003; Opromolla e Laurenti, 2011), mas só foi implantada no Brasil a partir de 1988, pelo uso combinando de drogas, possibilitando a cura da doença. Paralelamente desenvolveu-se intensa programação de treinamento de pessoal, revisão e implantação de normas, previsão e controle de medicamentos, municipalização das ações de controle da hanseníase (Opromolla e Laurenti, 2011);

(ii) o debate sobre a descentralização das ações de controle da hanseníase nos municípios teve início em 1985, com a reestruturação do sistema de saúde e, no ano seguinte, o Ministério da Saúde solicitou prioridade para o Programa de Hanseníase, tendo por objetivo o incremento da cobertura e a melhora da atenção ao hanseniano (Opromolla e Laurenti, 2011);

(iii) em 1986, acompanhando o contexto brasileiro de redemocratização política e busca da construção da democracia, foi realizada a VIII Conferência Nacional de Saúde, considerada um marco histórico por consagrar os princípios preconizados pelo Movimento da Reforma. Dentre suas recomendações inclui a redefinição do papel dos leprosários, levando muitos à transformação em hospitais gerais e outros, em centros de pesquisa;

(iv) também 1986, durante a 44a Assembleia Mundial de Saúde foi apresentada a primeira proposta de eliminação da hanseníase até o ano 2000 (Brasil, 2013); no mesmo ano elaboraram-se os "Projetos de Intervenção para o quinquênio 1986-1990", visando à descentralização e integração do programa Hanseníase na rede de serviços de saúde, à implantação e à sistematização de todas as ações de controle, de acordo com a complexidade dos serviços de saúde, com o apoio dos organismos internacionais (Opromolla e Laurenti, 2011).

\section{Considerações finais}

Seguindo os pressupostos já referidos, realizou-se levantamento sobre acervos (Sá e Rezende, 2014; Rezende, 2014; Rezende e Sá, 2016a), selecionou-se e analisou-se um conjunto de materiais audiovisuais sobre hanseníase em busca da descontinuidade histórica 
presente no domínio do arquivo, ou seja, buscou-se traçar e identificar enunciados de mudanças e transformações dos discursos no âmbito dos saberes e das práticas referidas à patologia no Brasil (Rezende e Sá, 2014; Rezende e Sá, 2016b; Sá e Rezende, 2017).

Generalizando os resultados alcançados pela análise da série de filmes pode-se afirmar que a metodologia praticada sobre filmes de uma mesma temática de diferentes períodos temporais pode proporcionar debates e reflexões sobre: (1) como determinado estado do conhecimento sobre a Lepra/ Hanseníase constituiu e foi constituído por meio de relações sociais e políticas em diferentes níveis e épocas; (2) como, a partir de quais mudanças nas configurações sociais em seus diferentes âmbitos e níveis, e em qual medida, produziu-se um deslocamento no modo de abordar e tratar a hanseníase no Brasil (Ducatti, 2007; Santos et al. 2008).

$\mathrm{Na}$ série de vídeos analisada enunciaram-se, mais específica e fortemente, questões relacionadas à capacitação dos profissionais da área da saúde para uma abordagem adequada ao desafio ainda não alcançado da erradicação da hanseníase no país. É bastante evidente como nessas obras se constituem diferentemente vozes das políticas oficiais de controle da hanseníase e vozes do interesse público sobre a doença. Na série de vídeos como um todo, multiplicam-se essas vozes, ao mesmo tempo em que, em alguns vídeos mais do que em outros, os autores se apropriam delas para melhor instituir uma voz única e oficial, favorável à nova política, e a todo o momento implicando o profissional de saúde (prováveis espectadores) e a ignorância da população no processo de controle e erradicação da doença. Pode-se observar ainda um deslocamento significativo no modo como os órgãos responsáveis por gerir e elaborar políticas de saúde destinadas à prevenção, manutenção e recuperação da saúde da população, concentraram seus esforços na constituição de uma abordagem multifacetada da hanseníase, tal como indicada pela conceituação ampliada de saúde, valorizando-se a luta contra os preconceitos, a atenção especial à formação/ capacitação dos profissionais de saúde, e o desenvolvimento de ações permanentes destinadas à informação correta da população.

Apesar do referencial e das questões de pesquisa apresentados neste trabalho irem além dos resultados encontrados, foi possível perceber que esses últimos mostram como a dimensão de fonte histórica dos documentários se fundamenta numa crítica dos documentos. Evidenciou-se que esses documentos não são testemunhos diretos do que dizem ou mostram, mas evidenciam a natureza dos gestos políticos e estéticos que os constroem, como se pode ver nos enunciados extraídos na pesquisa realizadaOs resultados obtidos por essa abordagem reforçam a possibilidade da construção de uma leitura historiográfica dos filmes científicos seja para discussões sobre a natureza da ciência pela abordagem epistemológica, seja para discussões sobre questões de vários níveis e esferas pela abordagem arqueológica, seja para uma integração de ambas. Pela análise arqueológica pode-se afirmar que os filmes expressam dimensões sociais da produção científica que são importantes para compreender como a ciência se relaciona com a política, a sociedade, a cultura e o poder na sua própria contemporaneidade. A contemporaneidade de uma ciência aponta as disputas, polêmicas e hegemonias que a cercam e mostram como a cientificidade é profundamente política e cultural.

A pesquisa histórica documental cumpriu a função de informar e enriquecer as leituras que podem ser feitas dos filmes e, isso interessa não apenas aos investigadores da imagem 
em movimento, mas a todos envolvidos e interessados por contextos educacionais e situações de aprendizagem. A apreciação de filmes informada por pesquisa histórica referida aos mesmos pode favorecer uma emancipação tanto do olhar sobre uma obra audiovisual, quanto do olhar sobre a natureza da ciência. Sob essa perspectiva, filmes do passado podem até ter perdido sua força como exemplos da arte do cinema, mas permitem algum nível de acesso, por exemplo, às tentativas de persuadir o público sobre a importância da ciência, da tecnologia e da medicina (Boon, 2008).

Resta a constatação de que existe um vasto campo aberto a investigações sobre acervos audiovisuais e filmes de arquivos nas áreas das Ciências da Saúde. Dentre elas destaca-se o aprofundamento da abordagem proposta e o estudo sobre as potencialidades dos arquivos audiovisuais, pela análise de outras séries de filmes de diferentes períodos sobre patologias constantes nos acervos investigados e ainda presentes ou retornadas nas pautas científica, médica e de saúde pública contemporâneas. Por outro lado, pode-se também constituir séries de filmes sobre diferentes temas pertencentes a um mesmo período, e ainda, aprofundar investigações nos Acervos, especialmente no do BRAVS.

\section{Referências}

Boon, T. (2008). Films of facts: a history of science in documentary films and television. Londres: Wallflower.

Brasil, Secretaria de Vigilância em Saúde. (2013). Boletim Epidemiológico, 44 (11), 1-12.

Campos, D. Q. (2017). Um saber montado: Georges Didi-Huberman a montar imagem e tempo. Aniki, 4 (2), 269-288.

Castro, E. (2009). Vocabulário de Foucault. Belo Horizonte: Autêntica.

Comolli, J. L. (2008). Mauvaises frequentations: document et spectacle. Regard sur les archives, 63. Paris: Images documentaires.

Didi-Huberman, G. (2003). Images malgré tout. Paris: Les Editions de Minuit.

Ducatti, I. (2007). Discurso científico e legitimação política: hanseníase e isolamento compulsório (Brasil, século XX). Projeto História, 34, 303-315.

Ferro, M. (1992). Cinema e História. Rio de Janeiro: Paz e Terra.

Foucault, M. (2005). A arqueologia do saber. 7a ed. Rio de Janeiro: Forense Universitária.

Le Goff, J. (1990). História e memória. Campinas: Unicamp.

Lins, C.; Rezende; L. A. e França, A. (2011) A noção de documento e a apropriação de imagens de arquivo no documentário ensaístico contemporâneo. Revista Galáxia, 21, 54-67.

Maciel, L. R.; Oliveira, M. L. W.; Gallo, M. E. N. e Damasco, M. S. (2003). Memories and history of Hansen's disease in Brazil told by witnesses (1960-2000). História, Ciências, Saúde-Manguinhos, 10 (supl.1), 308-336.

Moraes, A. F. (2007). Documentário em Saúde. A produção de Humberto Mauro no INCE. Revista Z Cultural, 4, 1-11.

Opromolla, P. A. e Laurenti, R. (2011). Controle da hanseníase no Estado de São Paulo: análise histórica. Revista de Saúde Publica, 45 (1), 195-203. 
Rezende, L. A. (2013). Documentário Científico em tensão com a representação e a comunicação. Em Anais digitais do Encontro de Estudos de Cinema e Audiovisual Socine, (XVI, 512-517). São Paulo: Socine.

Rezende, L. A. (2014). Documentário científico e acervos audiovisuais: endereçamento, campos de correlação e gestos estéticos-políticos. Em Anais de textos completos do XVII Encontro de Estudos de Cinema e Audiovisual Socine, (XVII, 448-457). São Paulo: Socine.

Rezende, L. A.; Sá, M. B.; Oliveira, K. e Tiago, S. F. S. (2012). Pesquisa documental sobre Combate à lepra no Brasil (1945): filmes científicos como fontes para o ensino de história da ciência. Em Atas do Encontro Nacional de Pesquisa em Educação em Ciências (VIII, 11 p.). Campinas: ENPEC.

Rezende, L. A. e Sá, M. B. (2014). Filme científico de arquivo para o ensino-aprendizagem de História da Ciência: discussão de aspectos fundamentais. Trabalho apresentado na III Conferencia Latino-americana de Historia, Filosofía y Didáctica de las ciencias, realizada em Santiago de Chile, de 17 a 19 de Novembro de 2014.

Rezende, L. A. e Sá, M. B. (2016a). Documentário científico e acervos audiovisuais: arqueologia da produção brasileira. Em Atas do V Encontro Anual da Associação de Investigadores da Imagem em Movimento, (V, 620-629). Lisboa: AIM.

Rezende, L. A. e Sá, M. B. (2016b). História da ciência e arquivo: a hanseníase em dois filmes brasileiros. Em Anais de textos completos do Encontro Socine de Estudos de Cinema e Audiovisual (XIX, 512-517). São Paulo: Socine.

Rezende, L. A. e Sá, M. B. (2017). Hanseníase no cinema: deslocamentos políticos em vídeos de um acervo. Em Anais de textos completos do Encontro Socine de Estudos de Cinema e Audiovisual (XX, 643-650). São Paulo: Socine.

Sá, M. B. (2011). Entre o governo dos outros e o governo de si: uma análise foucaultiana da liberdade e suas práticas em vídeos educativos do Nutes/ UFRJ. Tese (Doutorado) - Programa de Pós-Graduação em Educação em Ciências e Saúde do Núcleo de Tecnologia Educacional para a Saúde, UFRJ, Rio de Janeiro.

Sá, M. B. (2018). Política, ética e liberdade: uma análise foucaultiana de vídeos educativos para as Ciências da Saúde. Curitiba: Appris.

Sá, M. B e Rezende, L. A. (2014). Cinema científico e educativo em medicina, saúde pública e ciências: primeiras indicações de um levantamento da produção brasileira. Trabalho apresentado no XIV Seminário Nacional de História da Ciência e da Tecnologia, realizado em Belo Horizonte de 8 a 11 de outubro de 2014.

Sá, M. B. e Rezende, L. A. (2016). Filme científico de arquivo como ferramenta para o ensino de Ciências. Trabalho apresentado no III Congresso Latino-americano de Investigação em Didática das Ciências, realizado em Montevidéu de 6 a 8 de julho de 2016.

Santos, L. A. C.; Faria, L. e Menezes, R. F. (2008). Contrapontos da história da hanseníase no Brasil: cenários de estigma e confinamento. Revista Brasileira de Estudos Populares, 25 (1), 167-190.

Sorlin, P. (1985). Sociología del cine: La apertura para la historia de mañana. México: Fondo de Cultura Económica. 
Resumen: El artículo presenta un panorama de la elaboración de abordaje teórico y analítico para investigaciones sobre la producción del audiovisual educativo destinado al área de las Ciencias de la Salud, a partir de nociones del referencial foucaultiano. Teniendo como premisas fundamentales que (1) toda fabricación humana es histórica y política, siendo producida y produciendo saberes según configuraciones y contingencias de su tiempo, y que (2) los audiovisuales guardan historias de saberes y poderes, se realizó una investigación sobre materiales y acervos audiovisuales en busca de la discontinuidad histórica presente en el dominio del archivo en el ámbito de los saberes y de las prácticas. Se presentan las operaciones teóricas relevantes, los datos empíricos producidos por las investigaciones y los resultados obtenidos en los últimos 5 años. Generalizando los resultados se puede afirmar (1) que los audiovisuales no son testimonios directos de lo que dicen o muestran, pero evidencian la naturaleza de los gestos políticos y estéticos que los construyen, (2) que un doble enfoque histórico - epistemológico y arqueológico - refuerza la posibilidad de la construcción de una lectura historiográfica del audiovisual, y (3) que las películas expresan dimensiones sociales de la producción científica, posibilitando avanzar en la comprensión de cómo la ciencia se relaciona con la política, la sociedad, la cultura y el poder en su propia contemporaneidad.

Palabras clave: Producción audiovisual - Educación en ciencias de la salud - Historia epistemológica - Historia arqueogenealógica - Michel Foucault.

Abstract: This paper presents an overview of the development of theoretical and analytical approach to research on the production of educational audiovisual for the area of health sciences, based on notions of the Foucaultian referential. Taking as fundamental assumptions that (1) all human fabrication is historical and political, being produced and producing knowledge according to the configurations and contingencies of its time, and that (2) audiovisuals store stories of knowledge and powers, research was conducted on materials and audiovisual collections in search of the historical discontinuity present in the field of archive in the scope of knowledge and practices. Present the relevant theoretical operations, empirical data produced by research and the results obtained in the last five years of research. Generalizing the results it can be stated that: (1) audiovisuals are not direct testimonies of what they say or show, but they show the nature of the political and aesthetic gestures that construct them, (2) a double historical approach - epistemological and archaeological - reinforces the possibility of constructing a historiographical reading of the audiovisual, and (3) films express social dimensions of scientific production, important elements to understand how science relates to politics, society, culture and power in his own contemporary.

Keywords: Audiovisual production - Education in health sciences - Epistemological history - Archaeogenealogical history - Michel Foucault.

[Las traducciones de los abstracts fueron supervisadas por el autor de cada artículo] 